\title{
Keefektifan Teknik Drama Segitiga Karpman untuk Meningkatkan Keterampilan Empati Siswa Sekolah Menengah Pertama
}

\author{
Leny Latifah* \\ Program Studi Bimbingan dan Konseling, Fakultas Ilmu Pendidikan, Universitas Kanjuruhan Malang, \\ Jl. S. Supriadi No.48 Malang, Jawa Timur, Indonesia 65148 \\ *Penulis koresponden, e-mail: lenylatifah@unikama.ac.id
}

Artikel diterima: 27 Februari 2019; direvisi: 9 April 2019; disetujui: 11 April 2019

\begin{abstract}
Empathic skills encourage an individual to look into the problems more clearly and objectively. Without empathy, it is difficult to know what others are experiencing because it is not possible to feel and understand the conditions of others. The particular study aimed to determine the effectiveness of Karpman drama triangle technique to increase junior high school students' empathy skill. The research subjects were six students of eighth grade in Sekolah Menengah Pertama Negeri 1 Turen, Malang. The particular research was Quasi-Experiment using the pretest and posttest design. The instruments were student empathy scale; experimental guidelines; and observation guidelines. The study showed that Karpman drama triangle technique was effective to increase junior high school students' empathy skill.
\end{abstract}

Keywords: empathy; karpman drama triangle; junior high school students

\begin{abstract}
Abstrak: Keterampilan berempati mendorong seseorang untuk melihat permasalahan dengan lebih jernih dan objektif. Tanpa berempati, sulit untuk mengetahui apa yang sedang dialami orang lain karena tidak dapat merasakan perasaan dan memahami kondisi yang sedang dialami orang lain. Penelitian ini bertujuan mengetahui keefektifan teknik drama segitiga Karpman untuk meningkatkan keterampilan empati siswa sekolah menengah pertama (SMP). Subjek penelitian adalah enam siswa kelas delapan SMP Negeri 1 Turen, Malang. Penelitian ini merupakan penelitian Quasi Eksperimen dengan menggunakan desain pretest dan posttest. Instrumen yang digunakan adalah skala empati siswa; pedoman eksperimen; dan pedoman observasi. Hasil penelitian menunjukkan bahwa teknik drama segitiga Karpman efektif untuk meningkatkan keterampilan empati siswa SMP.
\end{abstract}

Kata kunci: empati; drama segitiga karpman; siswa SMP

\section{PENDAHULUAN}

Masa remaja terbagi ke dalam tiga fase (Batubara, 2016) yaitu: usia 12-15 tahun disebut masa remaja awal yang ditandai dengan perubahan fisik seperti percepatan pertumbuhan, kematangan kognitif dan emosi (Charles dkk., 2017); usia 15-18 tahun disebut masa remaja pertengahan dan usia 18-21 tahun disebut masa remaja akhir (Hary dkk., 2018). Siswa yang duduk di bangku SMP termasuk ke dalam fase remaja awal (Hasibuan \& Wulandari, 2016). Perkembangan remaja pada fase ini tidak hanya terjadi perubahan fisik, tetapi juga pada psikisnya (Lee dkk., 2014). Perubahan psikis remaja yang pesat dapat memicu timbulnya suatu permasalahan, karena pada saat ini remaja mengalami kesulitan dalam berinteraksi sosial, salah satunya adalah keterampilan berempati terhadap orang lain yang rendah (Van der Graaff dkk., 2014).

Berdasarkan hasil observasi yang dilakukan terhadap siswa kelas delapan yang berada pada rentang usia 12-15 tahun di SMP Negeri 1 Turen Malang, ditemukan perilaku siswa yang mengindikasikan rendahnya empati yang terjadi di lingkungan sekolah. Perilaku tersebut adalah kebiasaan mengejek 
teman; kurang bisa menghargai pendapat orang lain; dan masih mementingkan dirinya sendiri (sikap egois). Hal tersebut dapat memicu terjadinya permusuhan dan perkelahian. Berdasarkan hasil tanya jawab dengan guru Bimbingan dan Konseling (BK) diperoleh informasi bahwa karakteristik sebagian besar siswa cenderung individual. Hal ini dipaparkan beliau dengan peristiwa yang sering terjadi yaitu ketika ada teman yang kesulitan pelajaran, teman yang lain cenderung tidak peduli.

Rendahnya keterampilan berempati jika tidak segera ditangani dapat berdampak sangat besar (Brewer \& Kerslake, 2015). Contohnya ketika tidak ada kesadaran untuk tolong-menolong, tidak ada kemauan untuk membantu permasalahan yang sedang dialami teman dan tidak ada tenggang rasa antar teman, maka individu tersebut tidak akan bisa merasakan apa yang sedang dialami oleh orang lain (Allemand dkk., 2015). Rendahnya keterampilan berempati bahkan dapat membuat siswa tidak bisa mencapai tugas perkembangannya dalam hal membina hubungan baik dengan teman sebaya; tidak mengenal etika pergaulan dengan teman sebaya yang beragam latar belakang; tidak bisa menyadari pentingnya penerapan norma-norma dalam bergaul dengan teman sebaya dan tidak bisa bergaul dengan teman sebaya secara positif (Kardos dkk., 2017).

Upaya untuk meningkatkan empati siswa yang sudah dilakukan selama ini masih bersifat instruksional semata, yang pada hakikatnya hanya memerhatikan aspek kognitif siswa saja (Haryati dkk., 2017). Hal tersebut dapat diartikan bahwa selama ini guru BK hanya mengajarkan empati melalui ceramah di kelas. Namun, ada juga penelitian yang menunjukkan bahwa sinema dapat digunakan untuk meningkatkan empati (Auliyah \& Flurentin, 2016; Cahyaningrum dkk., 2018). Hal-hal yang berkaitan dengan penggunaan teknik drama bagi siswa di sekolah untuk meningkatkan suatu keterampilan masih sangat jarang dilakukan. Siswa kerap dituntut untuk mengembangkan kemampuan kognitifnya saja dan kurang dibimbing dalam mengembangkan kemampuan yang lain (Ramdhani, 2016).

BK di sekolah memiliki empat komponen dalam pelaksanaan layanan kepada siswa (Kiweewa dkk., 2018). Salah satu layanannya yaitu layanan responsif, dimana layanan responsif diberikan sebagai upaya kuratif dalam membantu siswa menyelesaikan masalah (Depdiknas, 2007). Layanan responsif dapat diartikan sebagai layanan konseling individual maupun kelompok (Mau dkk., 2016). Pada penelitian ini, jenis konseling yang digunakan adalah konseling kelompok pendekatan Analisis Transaksional (AT) dengan teknik drama segitiga Karpman (Ganzevoort, 2017). Drama segitiga Karpman dikembangkan oleh Stephen Karpman sebagai model psikologis dan sosial dari interaksi manusia (Shmelev, 2015). Drama segitiga Karpman merupakan teknik yang menggambarkan dinamika hubungan manusia melalui gambar segitiga dan mengidentifikasi adanya tiga peran di dalamnya, yaitu sebagai: korban (victim); penganiaya (persecutor); dan penyelamat (rescuer) (Samborska-Sablik \& Sablik, 2016). Drama segitiga Karpman menggambarkan siklus drama kehidupan manusia yang terjadi secara berputar-putar dan berulang-ulang ketika timbul suatu konflik (Shmelev, 2015). Selanjutnya menurut Widdowson, (2018) konseling AT adalah pendekatan konseling yang efektif digunakan oleh konselor dalam membantu penyelesaian masalah yang berhubungan dengan interaksi sosial dengan orang tua; teman; dan orang lain disekitarnya. Oleh karena itu, peneliti tertarik untuk menguji keefektifan teknik drama segitiga Karpman melalui pemberian stimulus berupa skenario untuk meningkatkan kesadaran dan emosi siswa untuk berempati.

\section{METODE}

Penelitian ini merupakan penelitian kuantitatif dengan rancangan eksperimen (Creswell \& Creswell, 2017). Peneliti menggunakan Pre-Experimental Design, dengan pola One Group Pretest-Postest Design (Creswell \& Creswell, 2017). Peneliti menggunakan teknik drama segitiga Karpman dengan sasaran yang telah diketahui kondisi awalnya sebelum diberikan perlakuan dalam teknik tersebut secara ringkas. Kelompok subjek akan diberikan pengukuran awal (pretest) dengan menggunakan skala perilaku empati. Kemudian diberikan treatment teknik drama segitiga Karpman pada kelompok subjek dan diakhiri dengan dilakukannya pengukuran akhir (posttest) menggunakan skala empati.

Populasi penelitian ini adalah siswa kelas delapan SMP Negeri 1 Turen Malang tahun ajaran 20172018 yang berjumlah 30 siswa. Peneliti menggunakan teknik purposive sampling untuk pemilihan kelompok subjek yang memiliki tingkat empati rendah. Berdasarkan hasil penyebaran skala empati siswa SMP, terdapat enam siswa yang memiliki tingkat empati yang rendah dan kemudian dijadikan 
sampel penelitian. Penelitian ini memiliki tiga tahap yaitu: (1) tahap persiapan, yang dimulai dengan melakukan studi literatur terhadap teori yang relevan mengenai teknik pelatihan yang digunakan, menyusun dan memvalidasi bahan perlakuan, serta menentukan kelompok pelaksanaan bimbingan; (2) tahap pelaksanaan penelitian; dan (3) tahap akhir penelitian

Data diolah dengan menggunakan statistik deskriptif kurva normal, dengan menentukan miring (rata-rata) (Nasution, 2017). Untuk menguji hipotesis penelitian tentang perubahan tingkat empati siswa sebelum dan setelah mendapatkan treatment, data diolah dengan mengunakan rumus Wilcoxon Signed Rank Test (WSRT).

\section{HASIL}

\section{Pretest Empati Siswa SMP}

Berdasarkan hasil pretest yang dilakukan kepada 30 siswa, terdapat enam siswa yang memiliki tingkat empati rendah. Keenam siswa tersebut adalah: APF yang memiliki skor empati 45; BP yang memiliki skor empati 38; NPA yang memiliki skor empati 47; NC yang memiliki skor empati 48; MFP yang memiliki skor empati 45; dan RHP yang memiliki skor empati 44. Enam siswa yang memiliki tingkat empati rendah tersebut akan diberikan treatment berupa teknik drama segitiga Karpman melalui kegiatan konseling kelompok AT selama tujuh kali pertemuan.

\section{Posttest Empati Siswa SMP}

Kegiatan posttest dilakukan di akhir pertemuan untuk mengetahui tingkat keberhasilan setelah dilakukan treatment dan mengetahui perubahan tingkat empati siswa. Penelitian ini tidak menggunakan kelompok kontrol. Berdasarkan hasil posttest, skor empati keenam subjek meningkat, secara lebih detail perbandingan skor pretest dan posttest disajikan pada tabel 1. Rata-rata skor empati siswa sesudah pemberian treatment berada pada kategori tinggi dan dapat dikatakan bahwa mayoritas siswa mengalami peningkatan empati.

\section{Pengujian Hipotesis}

Hipotesis dalam penelitian diuji dengan WSRT, yaitu bahwa penggunaan teknik drama segitiga Karpman efektif untuk meningkatkan empati siswa SMP. Dalam menguji hipotesis ini digunakan data skor pretest dan skor posttest dari kelompok eksperimen, hasil analisis menunjukkan Sig 0.028 yang berarti $<0,05$ sehingga diketahui bahwa teknik drama segitiga Karpman dapat meningkatkan empati siswa di SMP. Nilai beda (z) -2,201 pada derajat signifikan $0.005(<0.05)$ dan sig. $(2$-tailed) adalah 0,028. Jika probabilitas $>0,05$, maka $\mathrm{H}_{0}$ (hipotesis nol) diterima, $\mathrm{H}_{\mathrm{a}}$ (hipotesis alternatif) ditolak dan jika probabilitas $<0,05$ maka $\mathrm{H}_{0}$ (hipotesis nol) ditolak, $\mathrm{H}_{\mathrm{a}}$ (hipotesis alternatif) diterima (Ismail, 2018). Jadi dari hasil uji Wilcoxon menunjukkan bahwa sig.(2-tailed) $0,028<0,05$ artinya penggunaan teknik drama segitiga Karpman efektif untuk meningkatkan empati siswa SMP.

Tabel 1. Data Skor Kelompok Eksperimen

\begin{tabular}{ccccccc}
\hline \multirow{2}{*}{ No } & $\begin{array}{c}\text { Subjek } \\
\text { Penelitian }\end{array}$ & \multicolumn{2}{c}{ Sebelum } & Treatment & \multicolumn{3}{c}{ Sesudah Treatment } & \\
\cline { 3 - 6 } & Skor & Kriteria & Skor & Kriteria & \\
\hline 1 & APF & 45 & Rendah & 94 & Tinggi & 49 \\
2 & BP & 38 & Rendah & 86 & Tinggi & 48 \\
3 & NPA & 47 & Rendah & 88 & Tinggi & 41 \\
4 & NC & 48 & Rendah & 93 & Tinggi & 45 \\
5 & MFP & 45 & Rendah & 89 & Tinggi & 44 \\
6 & RHP & 44 & Rendah & 91 & Tinggi & 47 \\
\hline
\end{tabular}




\section{PEMBAHASAN}

Fenomena rendahnya empati siswa merupakan permasalahan yang harus ditangani. Guru mata pelajaran; guru BK; dan orangtua berperan penting dalam meningkatkan dan mengembangkan kemampuan siswa berempati (Silver dkk., 2018). Guru dan orangtua harus mampu mengidentifikasi perkembangan empati anak agar anak tumbuh menjadi manusia yang prososial bukan antisosial (Teding van Berkhout \& Malouff, 2016). Hal ini dikarenakan rendahnya empati berkorelasi dengan bullying; perilaku agresif; kekerasan dan penyimpangan sosial lainnya (Del Rey dkk., 2016). Tingkat empati yang rendah juga dapat menyebabkan munculnya perilaku seperti memperkosa; menyiksa dan perilakuperilaku kriminal yang psikopat (Vachon \& Lynam, 2016).

Empati merupakan sumber dari perubahan sikap individu (Doane dkk., 2014), yang terkait sangat erat dengan perilaku pro-sosial (Prot dkk., 2014). Ketika berempati, seorang individu dapat berbagi perasaan dengan orang lain dalam suasana suka maupun duka, kesediaan memberikan bantuan kepada orang lain baik materiil maupun moril dan juga kesediaan untuk bekerjasama dengan orang lain demi tercapainya suatu tujuan (Darmawan, 2017). Empati juga dapat meningkatkan harga diri individu (Schalkwijk dkk., 2016). Hubungan sosial merupakan media berkreasi dan menyebabkan tumbuhnya rasa harga diri dalam diri seseorang (Han, 2015). Tanpa adanya empati, dirasa sulit untuk mengetahui apa yang sedang dialami seseorang karena tidak dapat memasuki perasaan dan memahami kondisi yang sedang dialaminya (Hattula dkk., 2015).

Empati merupakan cara mempersepsi kerangka internal dan referensi orang lain dengan keakuran dan komponen emosional, seolah-olah seseorang menjadi orang lain, tetapi masih menyadari kondisinya yang seolah-olah tadi (Englander, 2014). Empati dikatakan akurat jika pemahaman individu terhadap keadaan orang lain benar, dalam arti sesuai dengan penghayatan orang yang diberi empati (Wijaya \& Naryoso, 2017). Keterampilan berempati pada remaja sangat penting untuk ditingkatkan, karena banyak permasalahan remaja yang disebabkan oleh rendahnya keterampilan berempati. Keterampilan berempati akan mendorong seseorang untuk melihat permasalahan dengan lebih jernih dan menempatkan objektivitas dalam memecahkan suatu masalah (Van Lissa dkk., 2016).

Pendidikan sebagai salah satu sarana untuk mengatasi masalah pribadi-sosial remaja harus memiliki fungsi dan peran dalam meningkatkan empati siswa (Below, 2016). Lewat pendidikan, diharapkan krisis dalam berbagai aspek sosial siswa dapat diatasi. Pendidikan akan melahirkan manusia yang berkualitas dan akan menjadi kekuatan utama dalam mengatasi dan memecahkan masalah pribadi-sosial yang dihadapi. Menciptakan sumber daya manusia yang berkualitas, yang berpegang pada norma dan nilai yang kuat, kinerja dan disiplin tinggi, dan sebaliknya bukan sumber daya manusia yang tidak berkualitas, lemah dalam pegangan norma dan nilai, rendah disiplin dan kinerja (Churcher, 2016).

Konseling AT adalah pendekatan konseling yang efektif digunakan oleh konselor sekolah dalam membantu penyelesaian masalah yang berhubungan dengan interaksi sosial antara siswa dengan: orangtua; teman; dan orang lain (Fulkerson, 2003). Salah satu teknik dalam konseling AT yang dinilai efektif untuk menganalisis komunikasi yang digunakan siswa ketika mengadakan transaksi dengan orang lain adalah teknik bermain peran (Xu dkk., 2016). Teknik bermain peran dalam pendekatan konseling AT yang bisa digunakan yaitu teknik drama segitiga Karpman. Drama segitiga Karpman menggambarkan peran dramatis tindakan manusia dalam kehidupan sehari-hari yang tidak stabil, tidak memuaskan, berulang, dan penuh emosi (Douglas, 2018).

Bermain peran adalah sarana untuk memperlancar penanaman nilai-nilai bimbingan kepada individu (Samborska-Sablik \& Sablik, 2016). Permainan peran atau drama segitiga Karpman memiliki kaitan dengan perubahan sikap (Newman, 2017), hal ini karena drama segitiga Karpman merupakan alat yang berguna untuk membantu individu memahami kondisi orang lain, (Fulkerson, 2003). Lewat drama segitiga Karpman, siswa akan memperoleh pemahaman mengenai apa yang sedang dipikirkan dan dirasakan oleh orang lain ketika berada pada posisi persecutor (penganiaya); victim (korban); dan rescuer (penengah), sehingga siswa dapat menunjukkan tindakan yang tepat sebagai wujud dari peningkatan empati yang telah dialaminya (Ganzevoort, 2017). Sebuah penelitian menunjukkan bahwa bahwa teknik segitiga Karpman efektif meningkatkan interaksi sosial siswa (Salma, 2017). Melalui drama segitiga Karpman, siswa diajarkan untuk dapat memecahkan masalah dengan memahami apa yang sedang dipikirkan dan dirasakan oleh orang lain ketika berada pada posisi persecutor; victim; dan rescuer. 


\section{SIMPULAN}

Penggunaan teknik drama segitiga Karpman efektif untuk meningkatkan empati siswa SMP. Secara tidak langsung, teknik drama segitiga Karpman juga bisa membuat anggota kelompok mengekspresikan perasaan sesuai dengan peran yang diperankan. Terkait dengan simpulan penelitian, peneliti memiliki beberapa saran, yaitu: (1) dalam penggunaan teknik drama segitiga Karpman guru BK seyogyanya memerhatikan: kesiapan guru BK; kesiapan siswa; serta ketersediaan waktu untuk bermain peran. Guru BK juga perlu memotivasi siswa dengan mengajukan pertanyaan-pertanyaan agar siswa memperoleh wawasan tentang keanekaragaman nilai-nilai yang dianggap berharga. Guru BK juga perlu memberikan jeda waktu antar treatment, agar hasil yang diperoleh siswa murni dari hasil treatment; (2) peneliti lain dapat melakukan penelitian lanjut dengan menggunakan kelompok kontrol agar dapat dilihat perbedaan antar kelompok dan menggunakan desain penelitian time series.

\section{DAFTAR RUJUKAN}

Allemand, M., Steiger, A. E., \& Fend, H. A. (2015). Empathy Development in Adolescence Predicts Social Competencies in Adulthood. Journal of Personality, 83(2), 229-241.

Auliyah, A., \& Flurentin, E. (2016). Efektifitas Penggunaan Media Film untuk Meningkatkan Empati Siswa Kelas VII SMP. Jurnal Kajian Bimbingan dan Konseling, 1(2), 19-26. https://doi.org/10.17977/um001v1i12016p019

Batubara, J. R. L. (2016). Adolescent Development (Perkembangan Remaja). Sari Pediatri, 12(1), 21-29.

Below, A. v. (2016). Education for Students of Physiotherapy: How to Learn Empathy-A Theatre Pedagogy Project-Bachelor Thesis: is Empathy Teachable Through Theatre Techniques. Physiotherapy, 102, e129e130.

Brewer, G., \& Kerslake, J. (2015). Cyberbullying, Self-Esteem, Empathy and Loneliness. Computers in Human Behavior, 48, 255-260.

Cahyaningrum, V. D., Handarini, D. M., \& Simon, I. M. (2018). Pengembangan Panduan Pelatihan Empati Menggunakan Teknik Sinema Edukasi untuk Mencegah Perilaku Bullying Siswa Sekolah Menengah Pertama. Jurnal Kajian Bimbingan dan Konseling, 3(3), 139-145. https://doi.org/10.17977/um001v3i32018p139

Charles, N. E., Mathias, C. W., Acheson, A., \& Dougherty, D. M. (2017). Preadolescent Sensation Seeking and Early Adolescent Stress Relate to At-Risk Adolescents' Substance Use by Age 15. Addictive Behaviors, 69, $1-7$.

Churcher, M. (2016). Can Empathy Be a Moral Resource? A Smithean Reply to Jesse Prinz. Dialogue: Canadian Philosophical Review/Revue Canadienne de Philosophie, 55(3), 429-447.

Creswell, J. W., \& Creswell, J. D. (2017). Research Design: Qualitative, Quantitative, and Mixed Methods Approaches. Thousand Oaks, CA: Sage Publications.

Darmawan, C. W. (2017). Hubungan Antara Konsep Diri dengan Perilaku Prososial Siswa SMA Muhammadiyah 1 Malang. Psikovidya, 19(2), 94-105.

Del Rey, R., Lazuras, L., Casas, J. A., Barkoukis, V., Ortega-Ruiz, R., \& Tsorbatzoudis, H. (2016). Does Empathy Predict (Cyber) Bullying Perpetration, and How do Age, Gender and Nationality Affect This Relationship? Learning and Individual Differences, 45, 275-281.

Depdiknas. (2007). Naskah Akademik Penataan Pendidikan Profesional Konselor dan Layanan Bimbingan dan Konseling dalam Jalur Pendidikan Formal. Jakarta: Departemen Pendidikan Nasional.

Doane, A. N., Pearson, M. R., \& Kelley, M. L. (2014). Predictors of Cyberbullying Perpetration among College Students: An Application of The Theory of Reasoned Action. Computers in Human Behavior, 36, 154-162.

Douglas, M. (2018). Using Transactional Analysis to Help Foster Parents Develop Therapeutic Parenting Skills. Transactional Analysis Journal, 48(4), 335-349.

Englander, M. (2014). Empathy Training from A Phenomenological Perspective. Journal of Phenomenological Psychology, 45(1), 5-26.

Fulkerson, M. (2003). Integrating The Karpman Drama Triangle With Choice Theory and Reality Therapy. International Journal of Reality Therapy, 23(1).

Ganzevoort, R. R. (2017). The Drama Triangle of Religion and Violence. Dalam Religion and Violence (hal. 17-29). Springer.

Han, S. Y. (2015). Effects of Adolescent Self-Conscious Emotion, Empathy, and Forgiveness on Prosocial Behavior by Gender and Age. Journal of Korean Home Management Association, 33(5), 117-131. 
Hary, S. S., Artawan, C. A., \& Wahyudi, A. T. (2018). Perancangan Komik Strip Mengenai Berbagai Macam Reaksi yang Ditunjukkan Penderita Terhadap Fobianya untuk Remaja 15-18 tahun. Jurnal DKV Adiwarna, $1(12)$.

Haryati, A., Wibowo, M. E., \& Mulawarman, M. (2017). Model Bimbingan Kelompok Teknik Sosiodrama untuk Meningkatkan Empati Siswa SMP. Jurnal Bimbingan Konseling, 6(1), 28-33.

Hasibuan, R. L., \& Wulandari, R. L. H. (2016). Efektivitas Rational Emotive Behavior Therapy (REBT) untuk Meningkatkan Self Esteem pada Siswa SMP Korban Bullying. Jurnal Psikologi, 11(2), 103-110.

Hattula, J. D., Herzog, W., Dahl, D. W., \& Reinecke, S. (2015). Managerial Empathy Facilitates Egocentric Predictions of Consumer Preferences. Journal of Marketing Research, 52(2), 235-252.

Ismail, H. F. (2018). Statistika untuk Penelitian Pendidikan dan Ilmu-Ilmu Sosial. Jakarta: Kencana.

Kardos, P., Leidner, B., Pléh, C., Soltész, P., \& Unoka, Z. (2017). Empathic People have More Friends: Empathic Abilities Predict Social Network Size and Position in Social Network Predicts Empathic Efforts. Social Networks, 50, 1-5.

Kiweewa, J. M., Knettel, B. A., \& Luke, M. M. (2018). Incorporating Comprehensive Counselling and Guidance Models into School Curricula in Sub-Saharan Africa. International Journal for the Advancement of Counselling, 40(2), 133-147.

Lee, F. S., Heimer, H., Giedd, J. N., Lein, E. S., Šestan, N., Weinberger, D. R., \& Casey, B. J. (2014). Adolescent Mental Health-Opportunity and Obligation. Science, 346(6209), 547-549.

Mau, W.-C. J., Li, J., \& Hoetmer, K. (2016). Transforming High School Counseling: Counselors' Roles, Practices, and Expectations for Students' Success. Administrative Issues Journal: Connecting Education, Practice, and Research, 6(2), 83-95.

Nasution, L. M. (2017). Statistik Deskriptif. Hikmah, 14(1), 49-55.

Newman, T. (2017). Creating the Role: How Dramatherapy Can Assist in Re/creating an Identity with Recovering Addicts. Dramatherapy, 38(2-3), 106-123.

Prot, S., Gentile, D. A., Anderson, C. A., Suzuki, K., Swing, E., Lim, K. M., ... Liuqing, W. (2014). Long-Term Relations among Prosocial-Media Use, Empathy, and Prosocial Behavior. Psychological Science, 25(2), $358-368$.

Ramdhani, N. (2016). Emosi Moral dan Empati pada Pelaku Perundungan-siber. Jurnal Psikologi, 43(1), 66-80.

Salma, F. N. (2017). Konseling Kelompok Analisis Transaksional Teknik Drama Segitiga Karpman untuk Meningkatkan Kemampuan Interaksi Sosial Peserta Didik. (Skripsi Tidak Diterbitkan) Universitas Sebelas Maret.

Samborska-Sablik, A., \& Sablik, Z. (2016). Patient-Doctor Relationship from Perspective of The Karpman Drama Triangle. Polski Merkuriusz Lekarski: Organ Polskiego Towarzystwa Lekarskiego, 41(245), 255-257.

Schalkwijk, F., Stams, G. J., Stegge, H., Dekker, J., \& Peen, J. (2016). The Conscience As A Regulatory Function: Empathy, Shame, Pride, Guilt, and Moral Orientation in Delinquent Adolescents. International Journal of Offender Therapy and Comparative Criminology, 60(6), 675-693.

Shmelev, I. M. (2015). Beyond The Drama Triangle: The Overcoming Self. Psychology. Journal of Higher School of Economics, 12(2), 133-149.

Silver, J., Caleshu, C., Casson-Parkin, S., \& Ormond, K. (2018). Mindfulness among Genetic Counselors is Associated with Increased Empathy and Work Engagement and Decreased Burnout and Compassion Fatigue. Journal of Genetic Counseling, 27(5), 1175-1186.

Teding van Berkhout, E., \& Malouff, J. M. (2016). The Efficacy of Empathy Training: A Meta-Analysis of Randomized Controlled Trials. Journal of Counseling Psychology, 63(1), 32.

Vachon, D. D., \& Lynam, D. R. (2016). Fixing the Problem with Empathy: Development and Validation of The Affective and Cognitive Measure of Empathy. Assessment, 23(2), 135-149.

Van der Graaff, J., Branje, S., De Wied, M., Hawk, S., Van Lier, P., \& Meeus, W. (2014). Perspective Taking and Empathic Concern in Adolescence: Gender Differences in Developmental Changes. Developmental Psychology, 50(3), 881.

Van Lissa, C. J., Hawk, S. T., Branje, S., Koot, H. M., \& Meeus, W. H. J. (2016). Common and Unique Associations of Adolescents' Affective and Cognitive Empathy Development with Conflict Behavior Towards Parents. Journal of Adolescence, 47, 60-70.

Widdowson, M. (2018). The Importance of Research in Transactional Analysis for Transactional Analysts. Transactional Analysis Journal, 48(1), 33-42. 
Wijaya, A. A., Naryoso, A. (2017). Komunikasi Interpersonal Lintas Generasi untuk Menghadapi Stres Akademik pada Anak. Interaksi Online, 18(2), 1-7.

Xu, X., Wang, Y., Wang, Y., Song, M., Xiao, W., \& Bai, Y. (2016). Role-Playing is An Effective Instructional Strategy for Genetic Counseling Training: an Investigation and Comparative Study. BMC Medical Education, $16(1), 235$. 